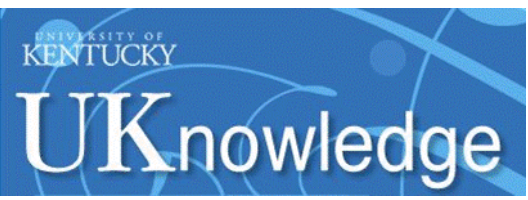

University of Kentucky

UKnowledge

$6-2019$

\title{
Initial Management of Meningiomas: Analysis of the National Cancer Database
}

\author{
Catherine R. Garcia \\ University of Kentucky \\ Stacey A. Slone \\ University of Kentucky, stacey.slone@uky.edu \\ Monica Chau \\ University of Kentucky, monica.chau@uky.edu \\ Janna H. Neltner \\ University of Kentucky, jmhack0@pop.uky.edu \\ Thomas A. Pittman \\ University of Kentucky, thomas.pittman@uky.edu
}

See next page for additional authors

Follow this and additional works at: https://uknowledge.uky.edu/neurology_facpub

Part of the Internal Medicine Commons, Neurology Commons, Neurosurgery Commons, Oncology Commons, and the Pathology Commons

Right click to open a feedback form in a new tab to let us know how this document benefits you.

\section{Repository Citation}

Garcia, Catherine R.; Slone, Stacey A.; Chau, Monica; Neltner, Janna H.; Pittman, Thomas A.; and Villano, John L., "Initial Management of Meningiomas: Analysis of the National Cancer Database" (2019).

Neurology Faculty Publications. 60.

https://uknowledge.uky.edu/neurology_facpub/60

This Article is brought to you for free and open access by the Neurology at UKnowledge. It has been accepted for inclusion in Neurology Faculty Publications by an authorized administrator of UKnowledge. For more information, please contact UKnowledge@lsv.uky.edu. 


\section{Initial Management of Meningiomas: Analysis of the National Cancer Database}

Digital Object Identifier (DOI)

https://doi.org/10.1016/j.canep.2019.02.018

Notes/Citation Information

Published in Cancer Epidemiology, v. 60.

(c) 2019 Elsevier Ltd.

(C) 2019. This manuscript version is made available under the CC-BY-NC-ND 4.0 license

https://creativecommons.org/licenses/by-nc-nd/4.0/

\section{Authors}

Catherine R. Garcia, Stacey A. Slone, Monica Chau, Janna H. Neltner, Thomas A. Pittman, and John L. Villano 
Published in final edited form as:

Cancer Epidemiol. 2019 June ; 60: 16-22. doi:10.1016/j.canep.2019.02.018.

\title{
Initial Management of Meningiomas: Analysis of the National Cancer Database Running Head: Management of Meningiomas
}

\author{
Catherine R. Garcia, MD, \\ Departments of Markey Cancer Center, University of Kentucky, Lexington, KY \\ Stacey A. Slone, MS, \\ Departments of Markey Cancer Center, University of Kentucky, Lexington, KY \\ Monica Chau, PhD, \\ Departments of Neurology, University of Kentucky, Lexington, KY
}

Janna H. Neltner, MD, Departments of Pathology, Division of Neuropathology, University of Kentucky, Lexington, KY

Thomas Pittman, MD, and

Departments of Neurosurgery, University of Kentucky, Lexington, KY

John L. Villano, MD, PhD

Departments of Medicine, Neurology, Neurosurgery, Markey Cancer Center, University of Kentucky, Lexington, KY

\section{Abstract}

Background: Meningiomas are the most common central nervous system tumor. We describe current trends in treatment and survival using the largest cancer dataset in the United States.

Methods: We analyzed the National Cancer Database from 2004-2014, for all patients with diagnosis of meningioma.

Results: 201,765 cases were analyzed. Patients were most commonly White (81.9\%) females (73.2\%) with a median age of 64 years. Fifty percent of patients were diagnosed by imaging. Patients were reported as grade I (24.9\%), grade II (5.0\%), grade III (0.7\%), or unknown WHO grade $(69.4 \%)$. Patients diagnosed by imaging were older, received treatment in community facilities, had higher Charlson-Deyo score, and a lower rate of private insurance. Watchful waiting was the most common treatment modality $(46.7 \%)$, followed by surgery only $(40 \%)$. Grade II and III patients were more likely to receive therapy. Watchful waiting increased from $35.2 \%$ in 2004 to $51.4 \%$ in 2014. Younger age, male gender, private insurance, and treatment in academic facilities were determinants for receipt of surgery and/or radiation. Median survival was 12.6 years, higher

Corresponding Author: John L. Villano, MD, PhD, University of Kentucky Markey Cancer Center 800 Rose Street, CC446, Lexington, KY, jlvillano@uky.edu, Tel: 859-323-0405, Fax: 859-257-7715.

Publisher's Disclaimer: This is a PDF file of an unedited manuscript that has been accepted for publication. As a service to our customers we are providing this early version of the manuscript. The manuscript will undergo copyediting, typesetting, and review of the resulting proof before it is published in its final citable form. Please note that during the production process errors may be discovered which could affect the content, and all legal disclaimers that apply to the journal pertain.

Declarations: The authors have no conflicts of interest. 
in histologically confirmed cases (13.1 years). Older patients, Blacks, males, those that received radiation and surgery, and were treated in community facilities had an increased risk of mortality.

Conclusions: Over half of patients were diagnosed by imaging, suggesting a higher role of clinical determinants over histological confirmation in treatment decisions. Watchful waiting as initial management is increasing. Our survival analysis favored histological confirmation. Patients receiving radiation and surgery had an increased risk of mortality.

\section{Keywords}

Meningiomas; National Cancer Database; Outcomes; survival; treatment

\section{INTRODUCTION}

Meningiomas are the most common central nervous system tumor with an incidence rate of 8.14/100,000 population from 2010-2014 in the United States [1]. Most meningiomas are benign, slow-growing, but with a consistent pattern of increasing incidence [2].

Meningiomas are classified based on morphologic criteria by the World Health Organization (WHO) into three groups (grade I-III) [3]. Tissue confirmation may be deferred in some patients, as meningiomas can be diagnosed by imaging [4,5], and are frequently diagnosed incidentally. In those cases, magnetic resonance imaging may be used to differentiate benign and atypical meningioma, based on tumor margins, edema, bone destruction, and diffusion coefficient $[6,7]$. Population-based studies estimate that around $90 \%$ are grade I (benign), $10 \%$ are grade II (borderline), and less than $3 \%$ are grade III (malignant) $[1,8]$.

Treatment approaches for meningiomas include either observation alone, radiation alone, or surgical resection with or without radiation, and rarely, in cases with progression, a trial of systemic treatment, although there are no FDA approved therapies. Patients may be treated conservatively in small, asymptomatic tumors, whereas radiation therapy is reserved to prevent further growth in high grade lesions or in cases where a complete resection cannot be performed [9], with limited level 1 evidence on treatment recommendations.

An early investigation using the National Cancer Database (NCDB) included cases from 1985 to 1988 and 1990 to 1992 [10]. Subsequent analyses of the NCDB focused on discussions of high-grade meningiomas $[9,11-13]$ and limited their cohorts to patients with surgical or histological confirmation; these investigations may not be representative of treatment or decision estimates of all patients with diagnosis of meningioma. In addition, a recent NCDB analysis focused on grade I intracranial meningiomas that included cases without WHO grade as grade I [14]. Data on the accuracy of imaging alone in determining WHO grade is limited [6, 7], and many of the patients without WHO grade reported may have had grade II or III disease, inconclusive pathology reports, contraindications, or refused to undergo biopsy or surgery. We provide an overall estimate on initial treatment decisions along with survival estimates for meningiomas in the United States. 


\section{METHODS}

We analyzed the NCDB from 2004-2014, for patients with diagnosis of meningioma using International Classification of Disease for Oncology (ICD-O-3) codes 9530-9534 and 95379539. The NCDB prospectively collects cancer patient data from over 1,500 American College of Surgeons Commission on Cancer $(\mathrm{CoC})$ accredited institutions in the United States [15-18].

Data in our analysis includes age at diagnosis, sex, race, Hispanic origin, comorbidities based on Charlson-Deyo score (CDS) [19], primary payer status, median income, education status (percentage of non-High school graduates), and residency area, as defined by the United States Department of Agriculture Economic Research Service based on the patient's residential zip code. Facility type was included as available, with community facilities defined as centers without graduate medical education.

Patients were divided into grade I, II, III, or unknown using the "cs_site_specific_factor_1," which codes WHO grade as stated in the pathology report. Treatment received was assessed as first course of treatment at any $\mathrm{CoC}$ facility. Treatment groups included: 1) surgery, 2) radiation, 3) chemotherapy; 4); radiation and chemotherapy; 5) radiation and surgery; 6) chemotherapy and surgery; 7) radiation, chemotherapy, and surgery; 8) no treatment (watchful waiting); and 9) unknown. No treatment (watchful waiting) was defined as not receiving radiation, chemotherapy, or surgery. Further lines of therapy and recurrence rate are not captured by the database and were therefore not considered for the study. Living region was defined as metropolitan (population of 250,000 or more), urban (2,500 to less than 250,000), and rural (less than 2,500).

Medians and inter-quartile ranges are presented for continuous variables and compared using Wilcoxon Rank Sum tests. For categorical variables, counts and percentages are presented and compared using chi-square tests. Kaplan Meier was employed to assess survival. Cox proportional hazards models were used to assess risk factors for mortality and receipt of treatment (surgery or radiation). The level of statistical significance was set at 0.05 for all tests conducted, and all analyses were performed with SAS software version 9.4 (SAS Statistical Institute, Cary, North Carolina).

\section{RESULTS}

A total of 201,765 cases of meningiomas were included in our analysis, with a female gender predominance $(73.2 \%)$. The median age was 64 (53-76) years, with $10.9 \%$ of patients younger than 44 years of age, $39.2 \%$ between 45 and 64 years, $21.9 \%$ between 65 and 74 years, and $28 \%$ older than 75 years of age. The most common race was White (81.9\%), followed by Black (12.2\%), and Other (4.3\%); 6.2\% were of Hispanic origin. The racial and ethnic distribution represent a significant variation compared to the United States population, where Whites account for 62\%, Blacks for 12.6\%, and 17.3\% are Hispanic [20]. Tumor location in the spine was reported in 1,054 (0.5\%) patients. 


\section{Diagnostic confirmation.}

Fifty percent of the patients were diagnosed by clinical and imaging criteria $(n=101,586)$, while 49.3\% (N=99,447) were confirmed histologically. Diagnosis confirmation was unknown in 732 patients. Patients diagnosed by clinical and imaging criteria were significantly older (median of 71 years) compared to patients diagnosed histologically (median of 59 years), were more commonly seen in community hospitals (50.4\% versus $34.8 \%$ ), had a slightly higher percentage of $\geq 3$ of CDS (3.6\% versus $2.4 \%$ ), had a lower frequency of private insurance (29.5\% versus $50.3 \%)$, and a higher percentage of patients covered by Medicare (58.8\% versus $34.7 \%$ ). We found no differences in gender, race, Hispanic origin, urban/rural status, education, or median income while comparing patients diagnosed by clinical and imaging criteria to those diagnosed with histological confirmation. In the clinical and imaging group $86.2 \%$ received no treatment, $10.5 \%$ received radiation, and $0.2 \%$ underwent any kind of surgery.

\section{WHO Grade.}

Overall, WHO grade was reported in $30.6 \%$ of the cases. Of these, grade I was reported in $50,282(81.4 \%)$, grade II in 10,183 (16.5\%), and grade III in 1,337 (2.2\%). CDS was found to be zero in $73.3 \%$ of the patients, remaining constant among grades. Grade I patients were significantly younger (median age of 58 years) and had a female gender predominance (73.2\%). Grade II and III patients were significantly older (age 60 and 64, respectively), and had a higher proportion of males ( $43.0 \%$ and $48.9 \%$, respectively). White race was the most common in all groups, however grade II meningiomas had a higher frequency of Black patients. Hispanic origin remained constant among groups.

\section{Treatment.}

Overall, $46.7 \%$ received no treatment, $44.8 \%$ underwent surgery, $9.6 \%$ received radiation, $0.5 \%$ received hormone therapy, and $0.2 \%$ received chemotherapy. Over $40 \%$ of patients were treated with surgery only (table 1 , figure 1). In grade III patients, $42.1 \%$ received surgery only, as compared to $86.4 \%$ of grade I, and $72.7 \%$ of grade II. Grade II and III patients were more likely to receive radiation ( $22.9 \%$ and $51.1 \%$, respectively), and chemotherapy ( $0.3 \%$ and $6.2 \%$, respectively) compared to grade I patients.

\section{Surgery.}

The extent of surgical resection was reported in $46.8 \%$ of patients. Of these, gross total resection was performed in 51.9\%. The frequency of gross total resection increased with grade and was highest in patients with anaplastic meningioma (59\%). Younger age, male gender, other race, Hispanic origin, private insurance, and treatment in an academic facility were identified as factors for receiving surgery (supplemental table 1).

\section{Radiation.}

The majority of patients received radiation after surgery $(\mathrm{N}=7,135 ; 97.9 \%)$. The sequence of radiation and surgery did not vary by WHO grade. The most common type of radiation was stereotactic radiosurgery (SRS), accounting for $55.3 \%$ of patients that received radiation, followed by external beam (43.4\%). Grade II and III patients were more likely to receive 
external beam radiation, while in patients without reported grade, SRS was the most common type of radiation. In grade I, external beam radiation was used slightly more than SRS (table 1). Older age, female gender, Hispanic origin, treatment in a community facility, and not having insurance were identified as factors for receiving radiation (supplemental table 2).

\section{Year of diagnosis.}

The type of treatment received varied significantly with each year of diagnosis. Watchful waiting increased significantly during the timeframe, from $35.2 \%$ to $51.4 \%$ (2004-2014). The use of radiation only and surgery only decreased progressively with more recent years of diagnosis (supplemental table 3).

\section{Socio-economic characteristics.}

The type of $\mathrm{CoC}$ facility was reported in $93 \%$ of the cases. Patients were treated in community facilities (42.8\%), academic hospitals (37.8\%), or integrated network hospitals (12.4\%). Grade III meningioma patients were more likely to be treated in community settings (34.1\%), compared to $30.1 \%$ of grade I, and $27.9 \%$ of grade II. Patients living in metropolitan areas accounted for $82.8 \%$ of the cohort, and $14.2 \%$ lived in urban/rural areas, remaining constant between WHO grade groups. Fifty-seven percent of patients lived in areas with $<12.9 \%$ of non-high school graduates. Overall, the most common type of insurance was Medicare (46.9\%), followed by private insurance (39.8\%). Medicare was more frequent in patients with anaplastic meningiomas. The majority of patients $(60.2 \%)$ had an annual income higher than $\$ 48,000$ per year. Socioeconomic factors did not vary by WHO grade.

\section{Survival.}

Median survival was 12.6 years overall. Survival varied significantly by WHO grade; was 11.9 years in grade II, 11.7 years in patients without grade reported, and 4.7 years in grade III (figure 2). Median survival could not be assessed in grade I as the survival rates were higher than $50 \%$ at the end of the follow-up period. Survival estimates were higher for younger patients, females, and non-Hispanics (table 2). Histological diagnostic confirmation was also associated with higher median survival (13.1 years) compared to patients diagnosed by clinical/imaging criteria (9.3 years) (figure 3 ). Patients that received surgery had 5-year survival estimates over $86 \%$, compared to $82.5 \%$ for patients that received radiation, $64.9 \%$ for patients who did not receive treatment, and $48.2 \%$ for patients that received chemotherapy.

Kaplan Meier survival estimates were assessed by type of radiation received; patients that underwent SRS were found to have higher survival estimates compared to external beam radiation in the overall population. Older age, Black race, male gender, receiving surgery plus radiation, and treatment in a community facility were identified as risk factors for mortality (table 3). Private insurance and overall higher socioeconomic status were protective factors for mortality. 


\section{DISCUSSION}

We provide a comprehensive analysis on patterns of care for meningiomas in the United States. This is important in a disease with an increasing incidence and long-term survival [8]. Over $50 \%$ of patients were diagnosed by clinical/imaging modalities alone, and $46.7 \%$ did not receive initial therapy. Survival has increased in comparison with previous studies, and our findings emphasize the role of clinical determinants in treatment decisions compared to histological confirmation or WHO grade.

NCDB is a valuable resource for long-term survival estimates, as it is one of the major sources for cancer care improvement [21]. One previous NCDB study presented an overall assessment of meningiomas and was published prior to wide use of modern imaging techniques [10]. Recent descriptions excluded patients without histological confirmation, or focused on specific and uncommon histological subgroups [10-14], limiting their findings to a selective patient population.

In our study, watchful waiting was the most common treatment modality (46.7\%), followed by surgery only. The use of watchful waiting increased progressively with each diagnosis year, as previously reported in an NCDB study for grade I intracranial meningioma [14]. Watchful waiting is an option for asymptomatic tumors, generally $<3 \mathrm{~cm}$; deferring surgical treatment until documentation on the pace of tumor growth [22,23]. This correlates with $50 \%$ of patients that were diagnosed by imaging, and the large number of patients without reported WHO grade, as meningiomas can be diagnosed incidentally or may be located in surgically challenging areas, such as the posterior fossa [5]. A strength of this study is the inclusion of patients without WHO grade reported along with a separate description of their outcomes and characteristics, reflecting common clinical practice scenario.

Patients without a reported WHO grade may be considered low-risk based on imaging and clinical examination, and over $65 \%$ of these patients were followed expectantly. These patients had a similar survival compared to grade II meningiomas in our cohort (figure 2). This group was also significantly older compared to grade I, and a had a higher number of patients with a CDS 23 . Previous NCDB investigations grouped these patients as WHO grade I, reporting 50\% not receiving initial therapy [14]. Imaging alone is not sufficient to establish grade; other reasons, including non-resectable tumors, inconclusive pathology reports, and contraindications for surgery, may play a role in the decision. From our analysis, $4.8 \%$ of grade I patients and $65.5 \%$ of patients with unknown grade did not receive initial treatment. Overall, the poorer outcomes of patients diagnosed by imaging only can be explained by older age, higher number of comorbidities, and possibly having locations or number of lesions preventing tissue confirmation. In addition, dural-based mesenchymal neoplasms, or dural metastases may mimic meningiomas by imaging [24].

The 5-year survival estimates were higher in patients that underwent surgical resection compared to those that did not receive treatment. However, a multivariate analysis did not confirm differences in overall mortality risk while comparing surgical resection alone to watchful waiting. Tumor growth is expected in patients that are followed expectantly and the decision to undergo surgery is based on degree of extension, proximity to critical central 
nervous system locations, irresectability or other contraindications for surgery [25], therefore the observed 5-year survival differences may be explained by patient selection alone (for surgery).

The use of radiation plus surgery was associated with mortality, as it is expected that patients who receive this treatment have higher grade lesions or non-resectable tumors. The use of radiation after surgery for grade II and III meningiomas has shown positive results, in a nonrandomized clinical trial [26], with results still to be finalized by the European Organization for Research and Treatment of Cancer (EORTC). The majority of data that supports this approach comes from retrospective analyses [27, 28], including previous NCDB descriptions of aggressive meningiomas (anaplastic and papillary) [11, 12], which may explain the differences in practice patterns with less than $23 \%$ of grade II and $51.1 \%$ of grade III tumors reporting its use. Interestingly, an NCDB investigation for atypical meningiomas showed an age related benefit of radiation ( $<55$ years and $>75$ years) [9]. Older age was a risk factor for mortality in our analysis, and was also a protective factor for receiving radiation, markedly between 65 and 74 years of age.

Radiation only may be used in non-resectable tumors, particularly in skull base, or optic nerve sheath meningiomas, and in elderly patients where retrospective analyses have demonstrated benefit $[9,29,30]$. Stereotactic radiosurgery and hypofractionated radiation alone have shown five-year tumor control rates over 84\% [31-33]. In our analysis, the most common type of radiation was SRS, and was more common in patients without reported WHO grade. External beam radiation was most common in grade II and III, and survival of these patients was decreased compared to SRS. This could be for many reasons, including patient selection bias for the more technologically advanced SRS, size and number of lesions, limitations in SRS tumor treatment compared to external beam radiation, and possibly as an indicator of higher quality care facility.

Hormone therapy was used in 1,094 patients, representing $0.5 \%$ of the cohort and was associated with increased mortality. This is at least partially explained because it is offered in patients with limited therapeutic options. The female predominance in benign meningioma and link to breast cancer suggests a possible sex hormone dependency tied to the growth of these tumors $[34,35]$. However, no therapeutic benefit has been found by targeting sex hormone receptors in clinical trials $[36,37]$. Somatostatin analogs initially showed benefits in case reports [38], but failed to be verified in clinical trials [39, 40].

Median survival was 12.6 years, and 5-year survival rates were $88.3 \%$ for grade I, $78.8 \%$ for grade II, $48.7 \%$ for grade III, and $71.9 \%$ for tumors without a reported WHO grade. This demonstrates an increased survival for meningiomas from that reported in previous analyses $[10,41]$. Interestingly, the survival in grade I and II meningiomas is higher than reported in previous NCDB analyses excluding imaging based diagnosed cases, but lower for grade III $(85.5 \%, 75.9 \%$, and $55.4 \%$, respectively) [13].

Patients with grade III meningiomas were more likely to receive adjuvant therapy, with $6.2 \%$ receiving chemotherapy as first course treatment although there is no Food and Drug Administration (FDA) approved chemotherapy. This is slightly smaller than the 7\% 
previously described [11], and is in keeping with the literature as chemotherapy has not shown survival benefits in meningiomas.

Treatment with chemotherapy only (without surgery or radiation therapy) showed the lowest 5 -year survival rates $(32.7 \%)$. This lower survival is expected as chemotherapy is used in cases of surgically inaccessible tumors and in patients who cannot receive further radiation therapy [42]. Hydroxyurea was dropped from the National Comprehensive Cancer Network (NCCN) guideline for WHO grade II meningiomas starting in 2009, based on the lack of survival benefits [42]. The only systemic therapies that have shown limited efficacy are somatostatin analogues, sunitinib, bevacizumab, everolimus, and interferon-alpha at recurrence [43-45]. Immunotherapy with immune checkpoint inhibitors may have a role in the future as evidence demonstrates PD-L1 expression in anaplastic meningiomas [46].

The main limitations of our study include the inability to evaluate cause of death, recurrence rate, individual patient characteristics, overall performance, further treatment lines, and the reasons behind treatment decisions. Our analysis provides a large-scale evaluation of the treatment and survival patterns of meningiomas in the United States, and highlights the increasing survival of meningiomas and the large number of cases diagnosed by imaging only. We believe our combined assessment provides a real-world picture of treatment and survival patterns of meningiomas, as treatment decisions are made before pathological confirmation. The observed 5-year survival differences between watchful waiting and surgery only, along with the use of chemotherapy in anaplastic lesions calls for prospective evaluations and the need for development of further systemic treatment approaches in patients with aggressive tumors or contraindications for surgery.

\section{Supplementary Material}

Refer to Web version on PubMed Central for supplementary material.

\section{Acknowledgments}

Funding: Ms. Slone is supported by the Biostatistics and Bioinformatics Shared Resource of the University of Kentucky Markey Cancer Center (P30 CA177558).

\section{REFERENCES}

[1]. Ostrom QT, Gittleman H, Xu J, Kromer C, Wolinsky Y, Kruchko C, Barnholtz-Sloan JS, CBTRUS Statistical Report: Primary Brain and Other Central Nervous System Tumors Diagnosed in the United States in 2009-2013, Neuro-oncology 18(suppl_5) (2016) v1-v75. [PubMed: 28475809]

[2]. Campbell BA, Jhamb A, Maguire JA, Toyota B, Ma R, Meningiomas in 2009: controversies and future challenges, American journal of clinical oncology 32(1) (2009) 73-85. [PubMed: 19194129]

[3]. Cavenee WK, Louis DN, Ohgaki H, Wiestler OD, International Agency for Research on Cancer., WHO classification of tumours of the central nervous system, Revised 4th edition. ed., International Agency For Research On Cancer, Lyon, 2016.

[4]. Zhang H, Rodiger LA, Shen T, Miao J, Oudkerk M, Preoperative subtyping of meningiomas by perfusion MR imaging, Neuroradiology 50(10) (2008) 835-40. [PubMed: 18542938]

[5]. Vernooij MW, Ikram MA, Tanghe HL, Vincent AJPE, Hofman A, Krestin GP, Niessen WJ, Breteler MMB, van der Lugt A, Incidental Findings on Brain MRI in the General Population, New England Journal of Medicine 357(18) (2007) 1821-1828. [PubMed: 17978290] 
[6]. Nagar VA, Ye JR, Ng WH, Chan YH, Hui F, Lee CK, Lim CC, Diffusion-weighted MR imaging: diagnosing atypical or malignant meningiomas and detecting tumor dedifferentiation, AJNR. American journal of neuroradiology 29(6) (2008) 1147-52. [PubMed: 18356472]

[7]. Wang S, Kim S, Zhang Y, Wang L, Lee EB, Syre P, Poptani H, Melhem ER, Lee JY, Determination of grade and subtype of meningiomas by using histogram analysis of diffusiontensor imaging metrics, Radiology 262(2) (2012) 584-92. [PubMed: 22084207]

[8]. Dolecek TA, Dressler EV, Thakkar JP, Liu M, Al-Qaisi A, Villano JL, Epidemiology of meningiomas post-Public Law 107-206: The Benign Brain Tumor Cancer Registries Amendment Act, Cancer 121(14) (2015) 2400-10. [PubMed: 25872752]

[9]. Barthelemy E, Loewenstern J, Konuthula N, Pain M, Hall J, Govindaraj S, Bederson J, Shrivastava RK, Primary management of atypical meningioma: treatment patterns and survival outcomes by patient age, J Cancer Res Clin Oncol (2018).

[10]. McCarthy BJ, Davis FG, Freels S, Surawicz TS, Damek DM, Grutsch J, Menck HR, Laws ER Jr., Factors associated with survival in patients with meningioma, J Neurosurg 88(5) (1998) 831-9. [PubMed: 9576250]

[11]. Orton A, Frandsen J, Jensen R, Shrieve DC, Suneja G, Anaplastic meningioma: an analysis of the National Cancer Database from 2004 to 2012, J Neurosurg (2017) 1-6.

[12]. Sumner WA, Amini A, Hankinson TC, Foreman NK, Gaspar LE, Kavanagh BD, Karam SD, Rusthoven CG, Liu AK, Survival benefit of postoperative radiation in papillary meningioma: Analysis of the National Cancer Data Base, Reports of practical oncology and radiotherapy : journal of Greatpoland Cancer Center in Poznan and Polish Society of Radiation Oncology 22(6) (2017) 495-501.

[13]. Rydzewski NR, Lesniak MS, Chandler JP, Kalapurakal JA, Pollom E, Tate MC, Bloch O, Kruser T, Dalal P, Sachdev S, Gross total resection and adjuvant radiotherapy most significant predictors of improved survival in patients with atypical meningioma, Cancer 124(4) (2018) 734-742. [PubMed: 29131312]

[14]. Dutta SW, Peterson JL, Vallow LA, Mahajan A, Rosenfeld SS, Quinones-Hinojosa A, Trifiletti DM, National care among patients with WHO grade I intracranial meningioma, J Clin Neurosci (2018).

[15]. Surawicz TS, Davis F, Freels S, Laws ER Jr., Menck HR, Brain tumor survival: results from the National Cancer Data Base, Journal of neuro-oncology 40(2) (1998) 151-60. [PubMed: 9892097]

[16]. Boffa DJ, Rosen JE, Mallin K, Loomis A, Gay G, Palis B, Thoburn K, Gress D, McKellar DP, Shulman LN, Facktor MA, Winchester DP, Using the National Cancer Database for Outcomes Research: A Review, JAMA oncology 3(12) (2017) 1722-1728. [PubMed: 28241198]

[17]. Chiu CH, Tsai CM, Chen YM, Chiang SC, Liou JL, Perng RP, Gefitinib is active in patients with brain metastases from non-small cell lung cancer and response is related to skin toxicity, Lung cancer (Amsterdam, Netherlands) 47(1) (2005) 129-38.

[18]. Raval MV, Bilimoria KY, Stewart AK, Bentrem DJ, Ko CY, Using the NCDB for cancer care improvement: an introduction to available quality assessment tools, Journal of surgical oncology 99(8) (2009) 488-90. [PubMed: 19466738]

[19]. Charlson ME, Pompei P, Ales KL, MacKenzie CR, A new method of classifying prognostic comorbidity in longitudinal studies: development and validation, Journal of chronic diseases 40(5) (1987) 373-83. [PubMed: 3558716]

[20]. U.S.C. Bureau, Annual Estimates of the Resident Population: April 1, 2010 to July 1, 2016

[21]. Winchester DP, Stewart AK, Phillips JL, Ward EE, The national cancer data base: past, present, and future, Annals of surgical oncology 17(1) (2010) 4-7. [PubMed: 19847564]

[22]. Nakamura M, Roser F, Michel J, Jacobs C, Samii M, The natural history of incidental meningiomas, Neurosurgery 53(1) (2003) 62-70; discussion 70-1. [PubMed: 12823874]

[23]. Yano S, Kuratsu J, Indications for surgery in patients with asymptomatic meningiomas based on an extensive experience, Journal of neurosurgery 105(4) (2006) 538-43. [PubMed: 17044555]

[24]. Chourmouzi D, Potsi S, Moumtzouoglou A, Papadopoulou E, Drevelegas K, Zaraboukas T, Drevelegas A, Dural lesions mimicking meningiomas: A pictorial essay, World Journal of Radiology 4(3) (2012) 75-82. [PubMed: 22468187] 
[25]. Kim KH, Kang SJ, Choi JW, Kong DS, Seol HJ, Nam DH, Lee JI, Clinical and radiological outcomes of proactive Gamma Knife surgery for asymptomatic meningiomas compared with the natural course without intervention, Journal of neurosurgery (2018) 1-10.

[26]. Rogers L, Zhang P, Vogelbaum MA, Perry A, Ashby LS, Modi JM, Alleman AM, Galvin J, Brachman D, Jenrette JM, De Groot J, Bovi JA, Werner-Wasik M, Knisely JPS, Mehta MP, Intermediate-risk meningioma: initial outcomes from NRG Oncology RTOG 0539, Journal of neurosurgery (2017) 1-13.

[27]. Jaaskelainen J, Haltia M, Servo A, Atypical and anaplastic meningiomas: radiology, surgery, radiotherapy, and outcome, Surgical neurology 25(3) (1986) 233-42. [PubMed: 3945904]

[28]. Balasubramanian SK, Sharma M, Silva D, Karivedu V, Schmitt P, Stevens GH, Barnett GH, Prayson RA, Elson P, Suh JH, Murphy ES, Chao ST, Longitudinal experience with WHO Grade III (anaplastic) meningiomas at a single institution, Journal of neuro-oncology 131(3) (2017) 555-563. [PubMed: 27864703]

[29]. Korah MP, Nowlan AW, Johnstone PA, Crocker IR, Radiation therapy alone for imaging-defined meningiomas, International journal of radiation oncology, biology, physics 76(1) (2010) 181-6.

[30]. Fokas E, Henzel M, Surber G, Hamm K, Engenhart-Cabillic R, Stereotactic radiotherapy of benign meningioma in the elderly: clinical outcome and toxicity in 121 patients, Radiotherapy and oncology : journal of the European Society for Therapeutic Radiology and Oncology 111(3) (2014) 457-62. [PubMed: 24813096]

[31]. Lee JY, Niranjan A, McInerney J, Kondziolka D, Flickinger JC, Lunsford LD, Stereotactic radiosurgery providing long-term tumor control of cavernous sinus meningiomas, Journal of neurosurgery 97(1) (2002) 65-72. [PubMed: 12134934]

[32]. Skeie BS, Enger PO, Skeie GO, Thorsen F, Pedersen PH, Gamma knife surgery of meningiomas involving the cavernous sinus: long-term follow-up of 100 patients, Neurosurgery 66(4) (2010) 661-8; discussion 668-9. [PubMed: 20305491]

[33]. Trippa F, Maranzano E, Costantini S, Giorni C, Hypofractionated stereotactic radiotherapy for intracranial meningiomas: preliminary results of a feasible trial, Journal of neurosurgical sciences 53(1) (2009) 7-11. [PubMed: 19322130]

[34]. Custer BS, Koepsell TD, Mueller BA, The association between breast carcinoma and meningioma in women, Cancer 94(6) (2002) 1626-35. [PubMed: 11920521]

[35]. Miller RE, Breast cancer and meningioma, Journal of surgical oncology 31(3) (1986) 182-3. [PubMed: 3724170]

[36]. Ji Y, Rankin C, Grunberg S, Sherrod AE, Ahmadi J, Townsend JJ, Feun LG, Fredericks RK, Russell CA, Kabbinavar FF, Stelzer KJ, Schott A, Verschraegen C, Double-Blind Phase III Randomized Trial of the Antiprogestin Agent Mifepristone in the Treatment of Unresectable Meningioma: SWOG S9005, Journal of clinical oncology : official journal of the American Society of Clinical Oncology 33(34) (2015) 4093-8. [PubMed: 26527781]

[37]. Goodwin JW, Crowley J, Eyre HJ, Stafford B, Jaeckle KA, Townsend JJ, A phase II evaluation of tamoxifen in unresectable or refractory meningiomas: a Southwest Oncology Group study, Journal of neuro-oncology 15(1) (1993) 75-7. [PubMed: 8455065]

[38]. Garcia-Luna PP, Relimpio F, Pumar A, Pereira JL, Leal-Cerro A, Trujillo F, Cortes A, Astorga R, Clinical use of octreotide in unresectable meningiomas. A report of three cases, Journal of neurosurgical sciences 37(4) (1993) 237-41. [PubMed: 7931648]

[39]. Simo M, Argyriou AA, Macia M, Plans G, Majos C, Vidal N, Gil M, Bruna J, Recurrent highgrade meningioma: a phase II trial with somatostatin analogue therapy, Cancer chemotherapy and pharmacology 73(5) (2014) 919-23. [PubMed: 24619496]

[40]. Norden AD, Ligon KL, Hammond SN, Muzikansky A, Reardon DA, Kaley TJ, Batchelor TT, Plotkin SR, Raizer JJ, Wong ET, Drappatz J, Lesser GJ, Haidar S, Beroukhim R, Lee EQ, Doherty L, Lafrankie D, Gaffey SC, Gerard M, Smith KH, McCluskey C, Phuphanich S, Wen PY, Phase II study of monthly pasireotide LAR (SOM230C) for recurrent or progressive meningioma, Neurology 84(3) (2015) 280-6. [PubMed: 25527270]

[41]. Aizer AA, Bi WL, Kandola MS, Lee EQ, Nayak L, Rinne ML, Norden AD, Beroukhim R, Reardon DA, Wen PY, Al-Mefty O, Arvold ND, Dunn IF, Alexander BM, Extent of resection and 
overall survival for patients with atypical and malignant meningioma, Cancer 121(24) (2015) 4376-81. [PubMed: 26308667]

[42]. Kim J, Kim KH, Kim YZ, The Clinical Outcome of Hydroxyurea Chemotherapy after Incomplete Resection of Atypical Meningiomas, Brain Tumor Res Treat 5(2) (2017) 77-86. [PubMed: 29188208]

[43]. Chamberlain MC, Glantz MJ, Fadul CE, Recurrent meningioma: salvage therapy with longacting somatostatin analogue, Neurology 69(10) (2007) 969-73. [PubMed: 17785665]

[44]. Chamberlain MC, Glantz MJ, Interferon-alpha for recurrent World Health Organization grade 1 intracranial meningiomas, Cancer 113(8) (2008) 2146-51. [PubMed: 18756531]

[45]. Kaley TJ, Wen P, Schiff D, Ligon K, Haidar S, Karimi S, Lassman AB, Nolan CP, DeAngelis LM, Gavrilovic I, Norden A, Drappatz J, Lee EQ, Purow B, Plotkin SR, Batchelor T, Abrey LE, Omuro A, Phase II trial of sunitinib for recurrent and progressive atypical and anaplastic meningioma, Neuro-oncology 17(1) (2015) 116-21. [PubMed: 25100872]

[46]. Du Z, Abedalthagafi M, Aizer AA, McHenry AR, Sun HH, Bray MA, Viramontes O, Machaidze R, Brastianos PK, Reardon DA, Dunn IF, Freeman GJ, Ligon KL, Carpenter AE, Alexander BM, Agar NY, Rodig SJ, Bradshaw EM, Santagata S, Increased expression of the immune modulatory molecule PD-L1 (CD274) in anaplastic meningioma, Oncotarget 6(7) (2015) 4704-16. [PubMed: 25609200] 


\section{HIGHLIGHTS}

- We describe current trends in treatment and survival using the largest clinical cancer dataset

- Over fifty percent of meningiomas were diagnosed by imaging

- Watchful waiting was the most common treatment modality, followed by surgery only

- $\quad$ Older patients, blacks, males, and community facilities had a higher risk of mortality 


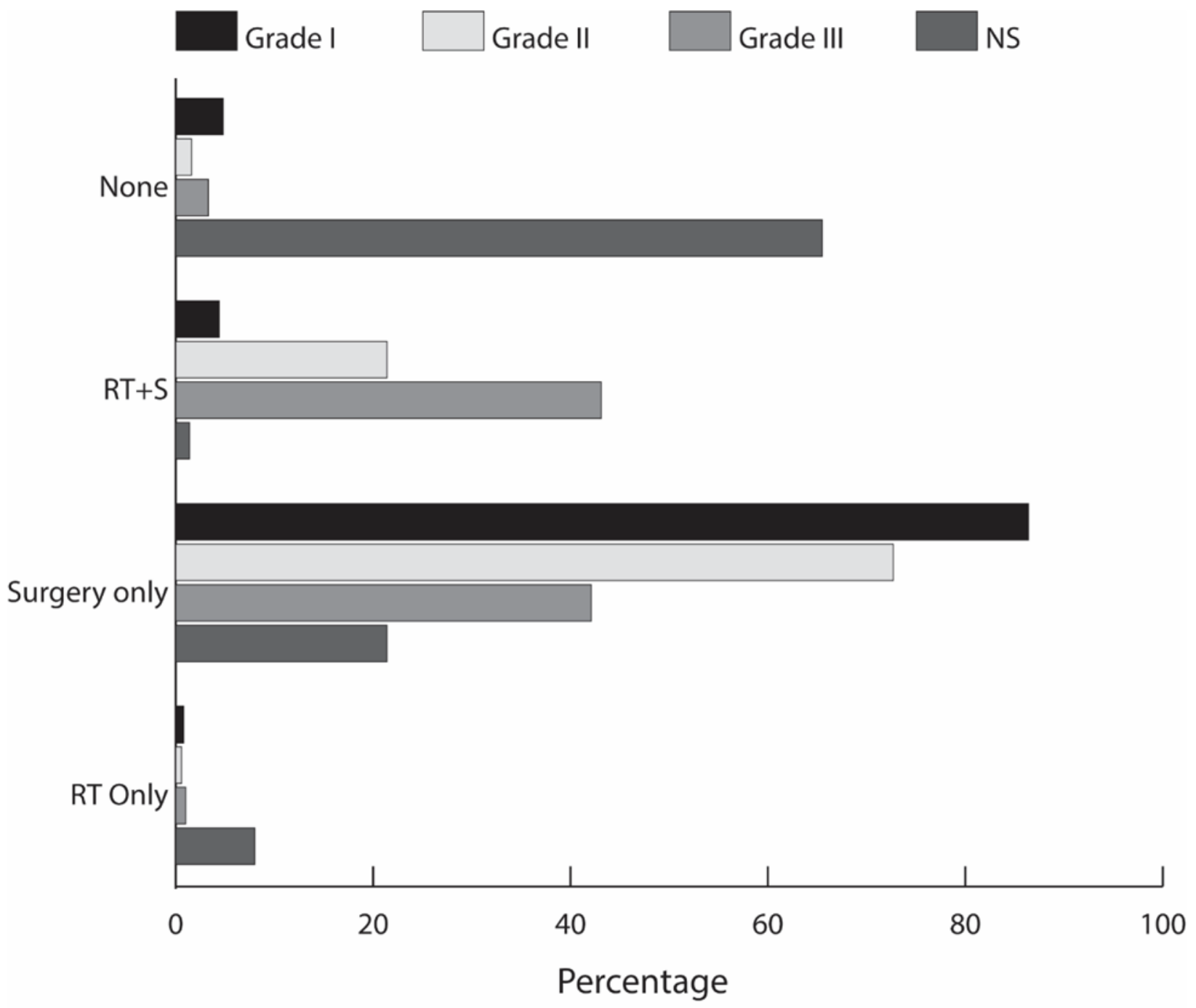

Figure 1.

Summary of treatment receipt overall and by WHO grade 


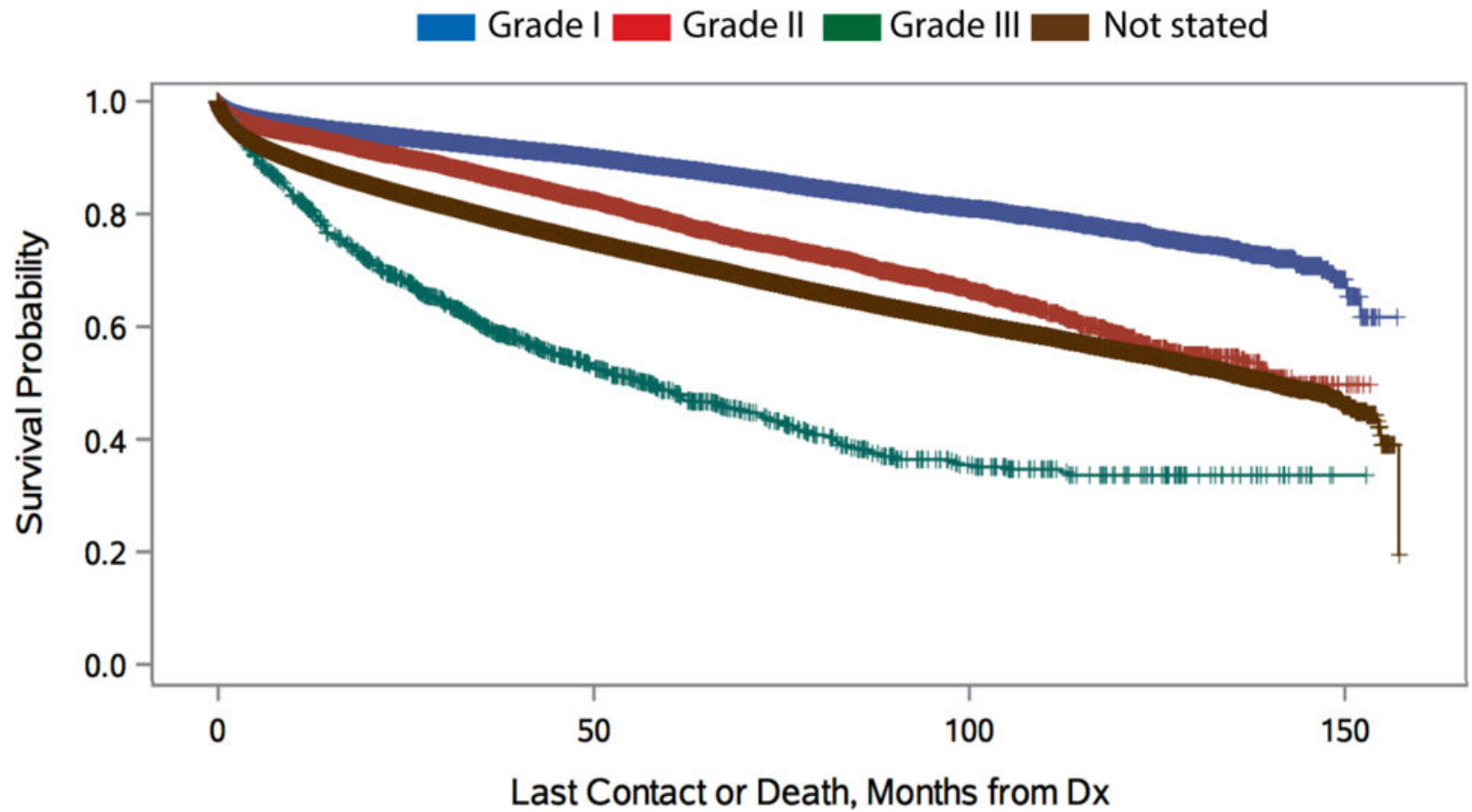

Figure 2.

Survival by WHO grade $(\mathrm{p}<0.001)$ 


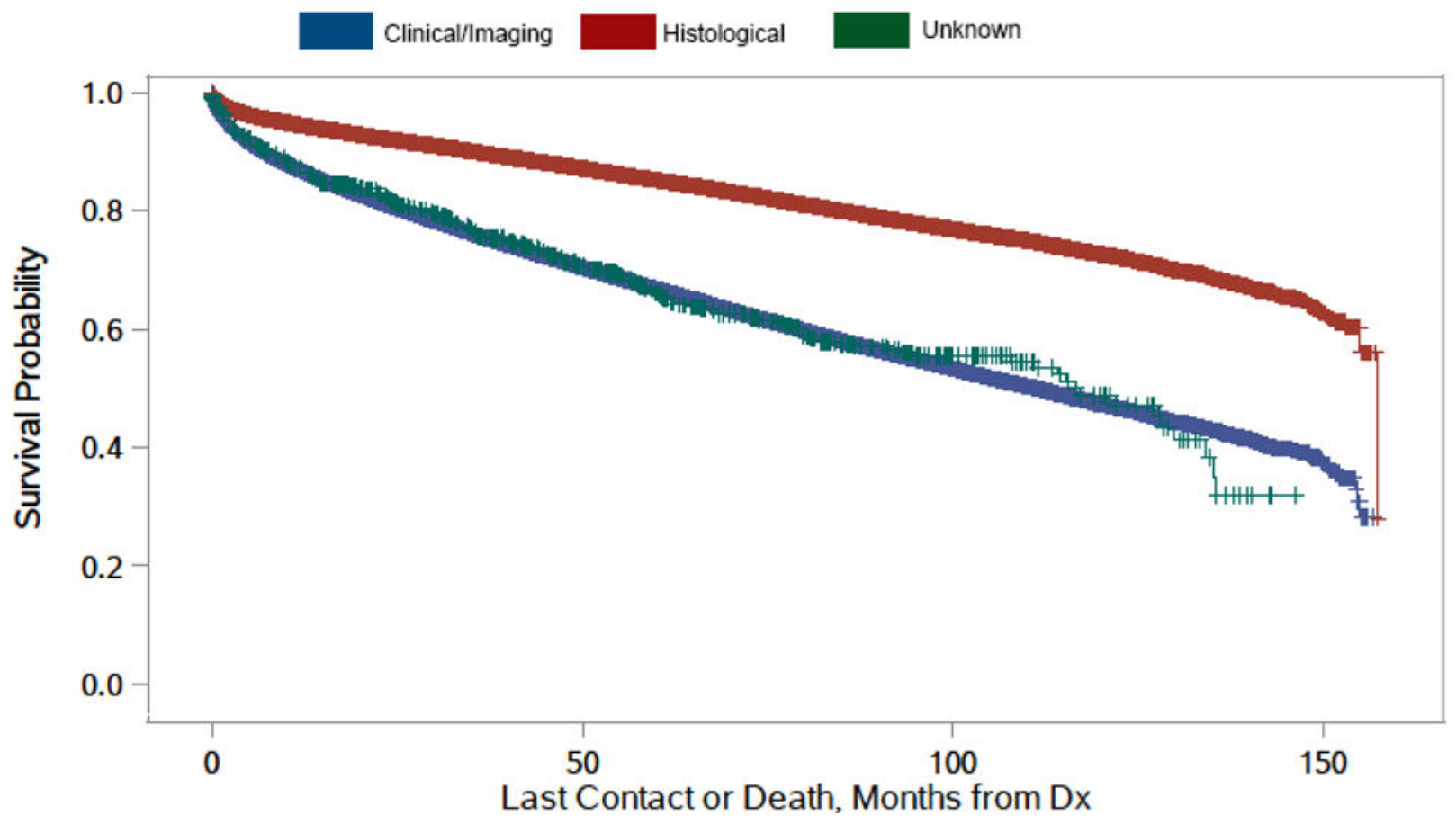

Figure 3.

Survival by type of diagnostic confirmation $(\mathrm{p}<0.001)$ 
Table 1.

Demographics and clinical characteristics of meningiomas, NCDB 2004-2014.

\begin{tabular}{|c|c|c|c|c|c|c|}
\hline & & Grade I N=50282 & Grade II N=10183 & Grade III N=1337 & Not Stated N=139963 & All N=201765 \\
\hline $\begin{array}{l}\text { Age in Years (median, } \\
\text { range) }\end{array}$ & & $58(48-68)$ & $60(48-70)$ & $64(52-74)$ & $67(55-79)$ & $64(53-76)$ \\
\hline \multirow[t]{2}{*}{ Gender } & Male & $13517(26.9 \%)$ & $4375(43.0 \%)$ & $654(48.9 \%)$ & $35503(25.4 \%)$ & $54049(26.8 \%)$ \\
\hline & Female & $36765(73.1 \%)$ & $5808(57.0 \%)$ & $683(51.1 \%)$ & $104460(74.6 \%)$ & $147716(73.2 \%)$ \\
\hline \multirow[t]{4}{*}{ Race } & Unknown & $857(1.7 \%)$ & $135(1.3 \%)$ & $22(1.6 \%)$ & $2091(1.5 \%)$ & $3105(1.5 \%)$ \\
\hline & White & $40908(81.4 \%)$ & $7986(78.4 \%)$ & $1081(80.9 \%)$ & $115329(82.4 \%)$ & $165304(81.9 \%)$ \\
\hline & Black & $5985(11.9 \%)$ & $1536(15.1 \%)$ & $173(12.9 \%)$ & $16919(12.1 \%)$ & $24613(12.2 \%)$ \\
\hline & Other & $2532(5.0 \%)$ & $526(5.2 \%)$ & $61(4.6 \%)$ & $5624(4.0 \%)$ & $8743(4.3 \%)$ \\
\hline \multirow[t]{3}{*}{ Hispanic Origin } & Unknown & $2837(5.6 \%)$ & $633(6.2 \%)$ & $77(5.8 \%)$ & $8146(5.8 \%)$ & $11693(5.8 \%)$ \\
\hline & No & $44014(87.5 \%)$ & $8905(87.4 \%)$ & $1169(87.4 \%)$ & $123386(88.2 \%)$ & $177474(88.0 \%)$ \\
\hline & Yes & $3431(6.8 \%)$ & $645(6.3 \%)$ & $91(6.8 \%)$ & $8431(6.0 \%)$ & $12598(6.2 \%)$ \\
\hline \multirow[t]{3}{*}{ Diagnostic Confirmation } & Unknown & $32(0.1 \%)$ & $1(0.0 \%)$ & $1(0.1 \%)$ & $698(0.5 \%)$ & $732(0.4 \%)$ \\
\hline & Histology & $48473(96.4 \%)$ & $10128(99.5 \%)$ & $1308(97.8 \%)$ & $39538(28.2 \%)$ & $99447(49.3 \%)$ \\
\hline & Clinical/Imaging & $1777(3.5 \%)$ & $54(0.5 \%)$ & $28(2.0 \%)$ & $99727(71.2 \%)$ & $101586(50.3 \%)$ \\
\hline \multirow[t]{4}{*}{ Charlson-Deyo Score } & 0 & $37175(73.9 \%)$ & $7223(70.9 \%)$ & $944(70.6 \%)$ & $102535(73.3 \%)$ & $147877(73.3 \%)$ \\
\hline & 1 & $9167(18.2 \%)$ & $1922(18.9 \%)$ & $252(18.8 \%)$ & $24333(17.4 \%)$ & $35674(17.7 \%)$ \\
\hline & 2 & $2759(5.5 \%)$ & $688(6.8 \%)$ & $95(7.1 \%)$ & $8539(6.1 \%)$ & $12081(6.0 \%)$ \\
\hline & 23 & $1181(2.3 \%)$ & $350(3.4 \%)$ & $46(3.4 \%)$ & $4556(3.3 \%)$ & $6133(3.0 \%)$ \\
\hline \multirow[t]{4}{*}{ Facility Type } & Unknown & $5095(10.1 \%)$ & $1286(12.6 \%)$ & $122(9.1 \%)$ & $7690(5.5 \%)$ & $14193(7.0 \%)$ \\
\hline & Community & $15158(30.1 \%)$ & $2843(27.9 \%)$ & $456(34.1 \%)$ & $67835(48.5 \%)$ & $86292(42.8 \%)$ \\
\hline & Academic & $23948(47.6 \%)$ & $4821(47.3 \%)$ & $599(44.8 \%)$ & $46951(33.5 \%)$ & $76319(37.8 \%)$ \\
\hline & Integrated Network & $6081(12.1 \%)$ & $1233(12.1 \%)$ & $160(12.0 \%)$ & $17487(12.5 \%)$ & $24961(12.4 \%)$ \\
\hline \multirow[t]{6}{*}{ Type of insurance } & Not Insured & $2203(4.4 \%)$ & $588(5.8 \%)$ & $53(4.0 \%)$ & $5165(3.7 \%)$ & $8009(4.0 \%)$ \\
\hline & Private Insurance & $26015(51.7 \%)$ & $4732(46.5 \%)$ & $558(41.7 \%)$ & $48946(35.0 \%)$ & $80251(39.8 \%)$ \\
\hline & Medicaid & $3683(7.3 \%)$ & $877(8.6 \%)$ & $90(6.7 \%)$ & $7575(5.4 \%)$ & $12225(6.1 \%)$ \\
\hline & Medicare & $16567(32.9 \%)$ & $3680(36.1 \%)$ & $591(44.2 \%)$ & $73741(52.7 \%)$ & $94579(46.9 \%)$ \\
\hline & Other Government & $716(1.4 \%)$ & $152(1.5 \%)$ & $24(1.8 \%)$ & $1357(1.0 \%)$ & $2249(1.1 \%)$ \\
\hline & Insurance Status Unknown & $1098(2.2 \%)$ & $154(1.5 \%)$ & $21(1.6 \%)$ & $3179(2.3 \%)$ & $4452(2.2 \%)$ \\
\hline \multirow{5}{*}{$\begin{array}{l}\text { Median Income } \\
\text { Quartiles 2007-2012 }\end{array}$} & Unknown & $348(0.7 \%)$ & $78(0.8 \%)$ & $21(1.6 \%)$ & $1473(1.1 \%)$ & $1920(1.0 \%)$ \\
\hline & $<\$ 38,000$ & $8318(16.5 \%)$ & $1807(17.7 \%)$ & $237(17.7 \%)$ & $24146(17.3 \%)$ & $34508(17.1 \%)$ \\
\hline & $\$ 38,000-\$ 47,999$ & $11254(22.4 \%)$ & $2354(23.1 \%)$ & $318(23.8 \%)$ & $32146(23.0 \%)$ & $46072(22.8 \%)$ \\
\hline & $\$ 48,000-\$ 62,999$ & $13434(26.7 \%)$ & $2694(26.5 \%)$ & $336(25.1 \%)$ & $37729(27.0 \%)$ & $54193(26.9 \%)$ \\
\hline & $2 \$ 68,000$ & $16928(33.7 \%)$ & $3250(31.9 \%)$ & $425(31.8 \%)$ & $44469(31.8 \%)$ & $65072(32.3 \%)$ \\
\hline \multirow{4}{*}{$\begin{array}{l}\text { Percent No High School } \\
\text { Degree 2007-2012 }\end{array}$} & Unknown & $327(0.7 \%)$ & $71(0.7 \%)$ & $20(1.5 \%)$ & $1412(1.0 \%)$ & $1830(0.9 \%)$ \\
\hline & $\geq 21 \%$ & $8335(16.6 \%)$ & $1769(17.4 \%)$ & $231(17.3 \%)$ & $24180(17.3 \%)$ & $34515(17.1 \%)$ \\
\hline & $13.0-20.9 \%$ & $12780(25.4 \%)$ & $2552(25.1 \%)$ & $351(26.3 \%)$ & $35302(25.2 \%)$ & $50985(25.3 \%)$ \\
\hline & $7.0-12.9 \%$ & $16058(31.9 \%)$ & $3263(32.0 \%)$ & $395(29.5 \%)$ & $44553(31.8 \%)$ & $64269(31.9 \%)$ \\
\hline
\end{tabular}




\begin{tabular}{|c|c|c|c|c|c|c|}
\hline & & Grade I N=50282 & Grade II N=10183 & Grade III N=1337 & Not Stated N=139963 & All N=201765 \\
\hline & $<7.0 \%$ & $12782(25.4 \%)$ & $2528(24.8 \%)$ & $340(25.4 \%)$ & $34516(24.7 \%)$ & $50166(24.9 \%)$ \\
\hline \multirow[t]{4}{*}{ Living Area } & Unknown & $1283(2.6 \%)$ & $272(2.7 \%)$ & $54(4.0 \%)$ & $4497(3.2 \%)$ & $6106(3.0 \%)$ \\
\hline & Metro & $41287(82.1 \%)$ & $8271(81.2 \%)$ & $1064(79.6 \%)$ & $116487(83.2 \%)$ & $167109(82.8 \%)$ \\
\hline & Urban & $5563(11.1 \%)$ & $1193(11.7 \%)$ & $157(11.7 \%)$ & $13645(9.7 \%)$ & $20558(10.2 \%)$ \\
\hline & Rural & $2149(4.3 \%)$ & $447(4.4 \%)$ & $62(4.6 \%)$ & $5334(3.8 \%)$ & $7992(4.0 \%)$ \\
\hline \multirow[t]{3}{*}{ Surgery } & Unknown & $917(1.8 \%)$ & $241(2.4 \%)$ & $27(2.0 \%)$ & $1453(1.0 \%)$ & $2638(1.3 \%)$ \\
\hline & None & $2908(5.8 \%)$ & $236(2.3 \%)$ & $64(4.8 \%)$ & $105531(75.4 \%)$ & $108739(53.9 \%)$ \\
\hline & Yes & $46457(92.4 \%)$ & $9706(95.3 \%)$ & $1246(93.2 \%)$ & $32979(23.6 \%)$ & $90388(44.8 \%)$ \\
\hline \multirow[t]{3}{*}{ Radiation } & Unknown & $555(1.1 \%)$ & $95(0.9 \%)$ & $16(1.2 \%)$ & $1568(1.1 \%)$ & $2234(1.1 \%)$ \\
\hline & No & $47000(93.5 \%)$ & $7759(76.2 \%)$ & $638(47.7 \%)$ & $124794(89.2 \%)$ & $180191(89.3 \%)$ \\
\hline & Yes & $2727(5.4 \%)$ & $2329(22.9 \%)$ & $683(51.1 \%)$ & $13601(9.7 \%)$ & $19340(9.6 \%)$ \\
\hline \multirow[t]{3}{*}{ Chemotherapy } & Unknown & $1455(2.9 \%)$ & $296(2.9 \%)$ & $53(4.0 \%)$ & $3805(2.7 \%)$ & $5609(2.8 \%)$ \\
\hline & No & $48783(97.0 \%)$ & $9852(96.7 \%)$ & $1201(89.8 \%)$ & $136004(97.2 \%)$ & $195840(97.1 \%)$ \\
\hline & Yes & $44(0.1 \%)$ & $35(0.3 \%)$ & $83(6.2 \%)$ & $154(0.1 \%)$ & $316(0.2 \%)$ \\
\hline \multirow[t]{9}{*}{ Treatment Summary } & Unknown & $1729(3.4 \%)$ & $343(3.4 \%)$ & $58(4.3 \%)$ & $4944(3.5 \%)$ & $7074(3.5 \%)$ \\
\hline & None & $2432(4.8 \%)$ & $162(1.6 \%)$ & $44(3.3 \%)$ & $91687(65.5 \%)$ & $94325(46.7 \%)$ \\
\hline & $\mathrm{RT}+\mathrm{CT}+\mathrm{S}$ & $11(0.0 \%)$ & $20(0.2 \%)$ & $63(4.7 \%)$ & $34(0.0 \%)$ & $128(0.1 \%)$ \\
\hline & $\mathrm{RT}+\mathrm{CT}$ & $4(0.0 \%)$ & $1(0.0 \%)$ & $4(0.3 \%)$ & $22(0.0 \%)$ & $31(0.0 \%)$ \\
\hline & $\mathrm{RT}+\mathrm{S}$ & $2232(4.4 \%)$ & $2176(21.4 \%)$ & $576(43.1 \%)$ & $1970(1.4 \%)$ & $6954(3.4 \%)$ \\
\hline & $\mathrm{CT}+\mathrm{S}$ & $27(0.1 \%)$ & $12(0.1 \%)$ & $14(1.0 \%)$ & $26(0.0 \%)$ & $79(0.0 \%)$ \\
\hline & Surgery only & $43433(86.4 \%)$ & $7404(72.7 \%)$ & $563(42.1 \%)$ & $29989(21.4 \%)$ & $81389(40.3 \%)$ \\
\hline & RT Only & $412(0.8 \%)$ & $63(0.6 \%)$ & $14(1.0 \%)$ & $11222(8.0 \%)$ & $11711(5.8 \%)$ \\
\hline & CT Only & $2(0.0 \%)$ & $2(0.0 \%)$ & $1(0.1 \%)$ & $69(0.0 \%)$ & $74(0.0 \%)$ \\
\hline
\end{tabular}

RT: Radiation; CT: Chemotherapy; S: Surgery 
Table 2.

5-year survival estimates by selected characteristics for meningiomas, NCDB 2004-2014.

\begin{tabular}{|l|l|l|l|}
\hline \multirow{4}{*}{ Age Group (years) } & & \# Cases & 5-year Survival (95\% CI) \\
\cline { 2 - 4 } & $0-44$ & 11072 & $95.5 \%(95.2 \%-95.9 \%)$ \\
\cline { 2 - 4 } & $45-64$ & 42462 & $89.8 \%(89.6 \%-90.0 \%)$ \\
\cline { 2 - 4 } & $65-74$ & 25355 & $77.3 \%(76.8 \%-77.7 \%)$ \\
\hline \multirow{5}{*}{ Gender } & 75 & 38462 & $48.7 \%(48.2 \%-49.2 \%)$ \\
\hline \multirow{5}{*}{ Race } & Female & 85035 & $78.2 \%(77.9 \%-78.4 \%)$ \\
\cline { 2 - 4 } & Male & 32316 & $70.3 \%(69.9 \%-70.8 \%)$ \\
\hline \multirow{5}{*}{ Hispanic Origin } & Black & 14114 & $75.2 \%(74.6 \%-75.8 \%)$ \\
\cline { 2 - 4 } & Other & 4281 & $82.4 \%(81.4 \%-83.3 \%)$ \\
\cline { 2 - 4 } & Unknown & 1767 & $84.4 \%(83.0 \%-85.9 \%)$ \\
\cline { 2 - 4 } & White & 97189 & $75.7 \%(75.5 \%-76.0 \%)$ \\
\cline { 2 - 4 } & No & 102931 & $75.6 \%(75.3 \%-75.8 \%)$ \\
\cline { 2 - 4 } & Unknown & 8223 & $76.7 \%(75.8 \%-77.5 \%)$ \\
\cline { 2 - 4 } & Yes & 6197 & $83.4 \%(82.6 \%-84.1 \%)$ \\
\hline Treatment Summary & None & 55684 & $64.9 \%(64.6 \%-65.3 \%)$ \\
\cline { 2 - 4 } & RT Only & 7099 & $81.9 \%(81.2 \%-82.7 \%)$ \\
\cline { 2 - 4 } & RT+S & 3874 & $83.7 \%(82.7 \%-84.7 \%)$ \\
\cline { 2 - 4 } & Surgery only & 46254 & $86.4 \%(86.1 \%-86.7 \%)$ \\
\hline & & & \\
\hline \multirow{5}{*}{} & & & \\
\hline
\end{tabular}

Number of patients who were alive 5 years after the diagnosis

RT: Radiation; CT: Chemotherapy; S: Surgery 
Table 3.

Multivariate analysis for risk factors for mortality in meningiomas, NCDB 2004-2014.

\begin{tabular}{|c|c|c|c|c|}
\hline & & Hazard Ratio & $\mathbf{9 5 \%} \mathrm{I}$ & Confidence Limits \\
\hline \multirow[t]{4}{*}{ Age Group (years) } & $\geq 75$ & 8.257 & 7.482 & 9.112 \\
\hline & $45-64$ & 1.809 & 1.642 & 1.993 \\
\hline & $65-74$ & 3.403 & 3.083 & 3.757 \\
\hline & $0-44$ & ref & - & - \\
\hline \multirow[t]{2}{*}{ Gender } & Male & 1.439 & 1.412 & 1.468 \\
\hline & Female & ref & - & - \\
\hline \multirow[t]{4}{*}{ Race } & Black & 1.419 & 1.337 & 1.505 \\
\hline & Unknown & 0.962 & 0.865 & 1.070 \\
\hline & White & 1.193 & 1.130 & 1.259 \\
\hline & Other & ref & - & - \\
\hline \multirow[t]{3}{*}{ Hispanic Origin } & Unknown & 1.044 & 1.005 & 1.084 \\
\hline & Yes & 0.829 & 0.791 & 0.869 \\
\hline & No & ref & - & - \\
\hline \multirow[t]{6}{*}{ Insurance } & Unknown & 0.916 & 0.834 & 1.006 \\
\hline & Medicaid & 1.241 & 1.145 & 1.345 \\
\hline & Medicare & 0.998 & 0.930 & 1.070 \\
\hline & Other Government & 0.973 & 0.861 & 1.099 \\
\hline & Private Insurance & 0.720 & 0.672 & 0.772 \\
\hline & Not insured & ref & - & - \\
\hline \multirow[t]{3}{*}{ Living Area } & Metro & 0.965 & 0.922 & 1.011 \\
\hline & Urban & 1.017 & 0.965 & 1.072 \\
\hline & Rural & ref & - & - \\
\hline \multirow[t]{3}{*}{ Facility Type } & Community & 1.125 & 1.102 & 1.148 \\
\hline & Integrated Network & 1.076 & 1.045 & 1.108 \\
\hline & Academic & ref & - & - \\
\hline \multirow[t]{9}{*}{ Treatment Summary } & CT Only & 3.268 & 0.447 & 23.878 \\
\hline & $\mathrm{CT}+\mathrm{S}$ & 1.792 & 0.241 & 13.298 \\
\hline & RT Only & 0.910 & 0.724 & 1.143 \\
\hline & $\mathrm{RT}+\mathrm{CT}$ & 3.970 & 0.520 & 30.327 \\
\hline & $\mathrm{RT}+\mathrm{CT}+\mathrm{S}$ & 2.770 & 0.379 & 20.273 \\
\hline & $\mathrm{RT}+\mathrm{S}$ & 1.365 & 1.052 & 1.773 \\
\hline & Surgery only & 1.035 & 0.919 & 1.165 \\
\hline & Unknown & 1.149 & 0.966 & 1.366 \\
\hline & None & ref & - & - \\
\hline
\end{tabular}

RT: Radiation; CT: Chemotherapy; S: Surgery 